\title{
Laboratory Indicators for Monitoring HIV Disease
}

\author{
Raul Scott Pereira ${ }^{+}$, Matthew Reginald Helbert
}

\author{
St. Helier Hospital, Carshalton, Surrey, SM5 1AA, U.K.
}

Immunological monitoring of disease progression following HIV infection and seroconversion illness, latency and AIDS, not only helps in the basic investigation of the natural history of the viral infection in man, but also can assist in prognosis and treatment of AIDS-defining illnesses. However, outside clinical trials, these tests should be selected and used in clinical practice only if they are validated as relevant and effective. The absolute CD4+ T-helper lymphocyte count, measured by flow cytometry, has emerged as the best available investigation, but needs care in sampling due to diurnal and circadian rhythms, effects of age, pregnancy, therapy, intercurrent infections and technique. Sampling should provide a baseline and trends - monthly intervals initially, then quarterly in uncomplicated cases. Thresholds may be given for counts (e.g. 200/ul) below which prophylaxis against pneumocystis pneumonia should be administered, and repeating persistently low counts (e.g. below 50/pl) is seldom helpful in practice. Serum levels of beta-2 microglobulin, neopterin and immunoglobulins rarely add information. Physicians and laboratories should have testing guidelines based on clinical audit of best practice, based in turn on scientific understanding of the immunological processes involved.

Key words: T helper - AIDS - neopterin - b2microglobulin - audit

Historically, the first diagnostic and monitoring tests for AIDS pre-dated the discovery of HIV. The use of serum beta2-microglobulin levels to predict those with a poor outlook in the GRID syndrome (Francioli et al. 1984, Zolla-Pazner et al. 1984); and the surrogate markers of positive serology to viruses such as Hepatitis B, EBV and CMV, were helpful in identifying the emerging epidemic. However, the discovery of HIV, and of the CD4-gp120 receptor-ligand interaction that gives the virus access to the cells of the immune system (Dalgleish et al. 1984), provided a rational basis for searches for predictive tests of immune damage in this rather unpredictable clinical syndrome.

The disruption caused by infection of CD4positive cells affects lymphocyte interaction with antigen-presenting cells (Helbert et al. 1993), their activation and the production of specific effector $\mathrm{T}$ cells and immunoglobulins - the classical pathways of immune function. There is evidence that HIV infection is followed by loss sequentially of $\mathrm{T}$ cell responsiveness in vitro to recall antigens, to allogeneic stimulation, and finally to lectins (Krohn et al. 1985, Clerici et al. 1989). More recently, functional $\mathrm{T}$ cell subsets and their cytokine products

\footnotetext{
Support for the analysis of techniques was provided by the UK Department of Health Medical Devices Directorate. Support for the audit described was provided by South West and South East Thames Regional AIDS funding and the South Thames HIV Physicians Group.

${ }^{+}$Corresponding author. Fax: 44-181-641.9193

Received 7 December 1995

Accepted 10 January 1996
}

have been investigated (Clerici \& Shearer 1993). Ideally, any test for these functions relying on simple enumeration, for example of lymphocyte subsets, should be validated by evidence that these subsets are functionally affected (Pereira \& PlattsMills 1982), but this is a counsel of perfection that may be unattainable in practice.

Functional tests of lymphoid cells in vitro are notoriously difficult to perform routinely, and the added complication of the need for containment of an untreatable virus still makes direct investigation of cellular interactions cumbersome. Numbers of cells, and measurement of their products in vivo, give data which can be relatively simply and safely obtained. However, their precision may give a spurious impression of predictive accuracy. Sophisticated statistical calculations of trends have been used (Galai et al. 1993), and these studies emphasise caution in extrapolation. Careful interpretation of these data in the light of what we now know about the disease is needed to give clinically and scientifically useful information.

Laboratories often send their results into a void, hoping that interpretation of their carefully obtained and validated data will be sensible and clinically helpful. However, the current thrust of clinical audit in many countries, together with financial constraints, has prompted a more pro-active role, with attempts to ensure that tests are requested appropriately and interpreted properly, and that 'best practice' guidelines are produced and followed. These studies were devised in order to help formulate such guidelines using the best available data and advice based on scientific rationale. 


\section{MATERIALS AND METHODS}

Patients - Data was obtained from a cohort of HIV-seropositive patients referred for testing from the South Thames Region over eight years; in the audit year this currently amounted to approximately 2000 patients unselected for age, race, sex, time from infection, or source of infection. Blood samples for lymphocyte subset enumeration were tested within $48 \mathrm{hr}$.

Lymphocyte subset enumeration - Initial validation of testing methods was performed in a study for the Department of Health UK (Owainati et al. 1990), and compared manual counting by immunofluorescence microscopy with direct-labelled monoclonal antibody, with flow cytometry using a research cell sorter (Coulter EPICS-V) and routine bench-top analysers then available (BectonDickinson FACScan and Coulter Profile) machines; statistical analysis used a computerised program (Bland \& Altman 1986). Absolute cell counts were derived from automated haematological machines (Coulter STKS and Technicon H1), and these were also compared (Robinson et al. 1992). Laboratory techniques and reagents for the audit studies followed CDC guidelines (CDC 1992).

Audit - Laboratories participating in the audit included all five centres within the South Thames Region, providing services to 15 clinical centres from the same region. The audit was done with the support and under the auspices of the South Thames HIV Physicians Group, and the Thames Regions Immunology Audit Group. Questionnaires were administered and results analysed by the Regional AIDS audit assistants in January 1995, with group meeting (moderator Dr AG Bird) and 'best practice' guideline production.

\section{RESULTS}

Subset quantitation methods - A manual method was compared with results from a research fluorescence activated cell sorter and two bench-top flow cytometers. The mean difference and agreement (confidence) limits for absolute counts and percentages of cell subsets in 35 sequential patient samples analysed optimally by the two methods (manual and flow cytometric) is shown in Table I. A scatter diagram of individual results of differences from the mean for CD4+ lymphocyte counts is shown graphically in Figure. There is significant scatter but minimal bias about the mean, suggesting that the manual method, even in skilled hands, is significantly unreliable at all levels of count and percentage. Comparison of machine methods and reagents confirmed better reproducibility (data not presented; Owainati et al. 1990).

Audit questionnaire - There were 26 physician replies from 15 centres in the region, and 5 replies from the 5 laboratories. The results are shown in Tables II, III and IV.

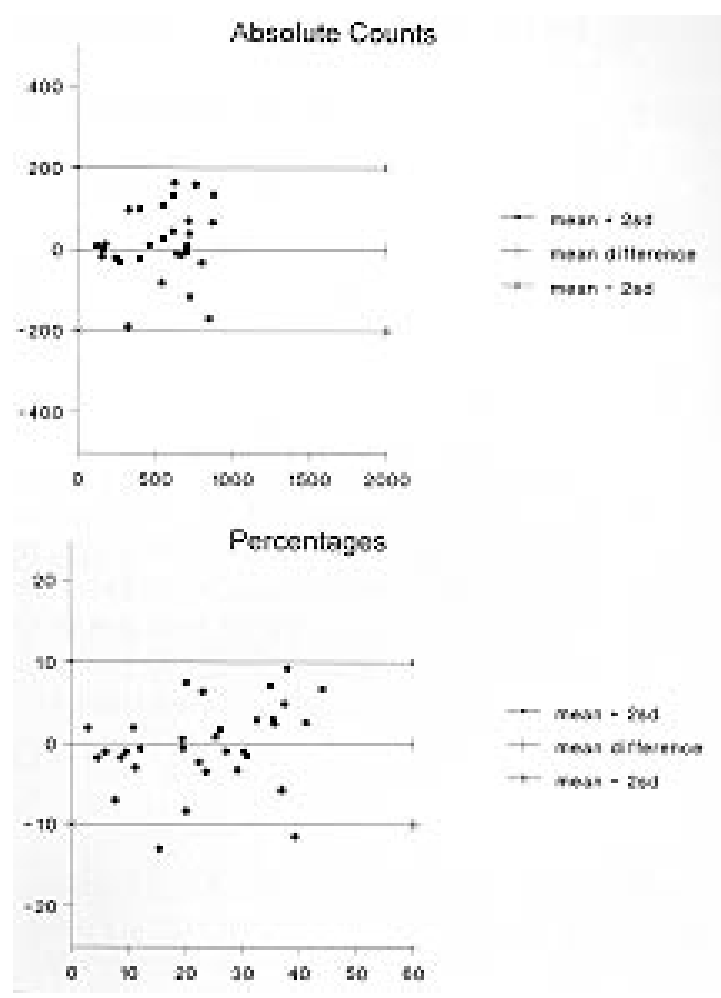

Flow cytometric counting versus microscopic counting of CD4+ lymphocytes.

Guidelines developed for initial CD4 counts Baseline CD4 counts: monthly counts for three months after HIV+ diagnosis. Threshold for $P C P$ prophylaxis: CD4 count $<200 / \mu \mathrm{l}\left(<0.2 \times 10^{9} /\right.$ litre $)$. Threshold for antiviral/ MAI therapy: CD4 count $<50 / \mu \mathrm{l}$ (<0.05 X 10\%/litre). Threshold for discontinuing counts: three CD4 counts $<50 / \mu \mathrm{l}(<0.05 \mathrm{X}$ $10^{9}$ /litre)

Guidelines developed for serum tests - Serum levels of beta2-microglobulin and neopterin: optional at diagnosis/monitoring. Laboratory advice was that these measurements changed slowly, and should be used at long intervals (e.g. annually) during monitoring (Bird 1992).

Guidelines developed for monitoring CD4 counts - Asymptomatic patients: CD4 counts halfyearly. Symptomatic patients: CD4 counts quarterly; rapid progressors: CD4 counts monthly.

\section{DISCUSSION}

Progression of HIV disease to AIDS is an immunologically mediated process, and this should be measurable by immunological parameters. The problem is to select a minimum practical set of such parameters that give enough reliable information on which to base decisions. Data presented here suggest that a current consensus would select the trend in the absolute CD4+ve T lymphocyte count in peripheral blood, with the optional addition of serum beta2-microglobulin and neopterin, on 
TABLE I

Flow cytometric analysis versus microscope counting

\begin{tabular}{lccccc}
\hline Cell type & Mean difference & SD & Mean-2SD & Mean+2SD & Range $^{a}$ \\
\hline T(CD3+)absolute & 72 & 154 & -238 & 380 & $50-3366$ \\
CD3+ percentage & 3.6 & 10.1 & -17.2 & 23.8 & $53 \%-96 \%$ \\
B(CD19+)absolute & 1 & 57 & -113 & 115 & $6-747$ \\
CD19+ percentage & 0.15 & 3.8 & -7.6 & 7.6 & $2 \%-28 \%$ \\
Tc (CD8+)absolute & 110 & 232 & -354 & 574 & $60-2270$ \\
CD8+ percentage & 7.2 & 8.6 & -10 & 24.4 & $29 \%-88 \%$ \\
Th $($ CD4+)absolute & -7 & 90 & -187 & 173 & $1-1461$ \\
CD4+ percentage & -0.4 & 4.5 & -9.4 & 8.6 & $1 \%-46 \%$ \\
\hline
\end{tabular}

$a$ : range by flow cytometric analysis

TABLE II

Demographic details, and physician and laboratory opinions before guidelines

\begin{tabular}{lrrrr}
\hline & \multicolumn{2}{c}{ Physicians $(26)$} & \multicolumn{2}{c}{ Laboratories (5) } \\
\hline Demographic details & Mean & Range & Mean & Range \\
Number of HIV-infected people monitored & 135 & $6-600$ & 363 & $50-750$ \\
Number of AIDS notifications in 1994 & 83 & $2-36$ & 188 & $10-400$ \\
& Mode & Range & Mode & Range \\
Baseline CD4 specimens recommended & 2 & $1-3$ & 3 & 1 \\
Intervals between baseline counts $($ months) & 3 & $1-6$ & 50 & $0-50$ \\
Threshold for discontinuing CD4 count $(/ \mu \mathrm{l})$ & 50 & $0-100$ & 200 & 200 \\
Threshold for PCP prophylaxis $(/ \mu \mathrm{l})$ & 200 & $200-300$ & not given \\
Threshold for anti-viral therapy $(/ \mu \mathrm{l})$ & 200 & $100-500$ & not given \\
Threshold for MAI prophylaxis $(/ \mu \mathrm{l})$ & 100 & $50-100$ & & \\
\hline
\end{tabular}

TABLE III

Physician monitoring practice before guidelines - serum levels

\begin{tabular}{lccc}
\hline & Ig levels & beta2microglobulin & neopterin \\
\hline Baseline tests & $5 / 26(19 \%)$ & $5 / 26(19 \%)$ & $1 / 26(4 \%)$ \\
Monitoring tests & 0 & $7 / 26(27 \%)$ & $1 / 26(4 \%)$ \\
Lab recommended & $1 / 5(20 \%)$ & $2 / 5(40 \%)$ & $1 / 5(20 \%)$ \\
\hline
\end{tabular}

TABLE IV

Physician monitoring practice before guidelines - CD4 counts

\begin{tabular}{lcccc}
\hline Intervals between CD4 monitoring tests & Monthly & Quarterly & Half-yearly & Other \\
\hline Asymptomatic HIV+ patients & 0 & 16 & 8 & 2 \\
Symptomatic HIV+ patients & 3 & 17 & 1 & 5 \\
With AIDS diagnosis & 1 & 13 & 2 & 9 \\
Following CD4 count $>500 / \mu \mathrm{l}$ & 0 & 14 & 3 & 2 \\
Following CD4 count $<500 / \mu \mathrm{l}$ & 6 & 17 & 2 & 0 \\
Following CD4 count $<200 / \mu \mathrm{l}$ & 5 & 4 & 0 & 2 \\
With rapidly falling CD4 count & 22 & 17 & 0 & 0 \\
Who is aged over 40 & 1 & & & 0 \\
\hline
\end{tabular}


which to base decisions on pneumocystis pneumonia prophylaxis, prophylaxis of atypical mycobacterial infection and azidothymidine treatment; in paediatric practice, the thresholds for pneumocystis treatment being age-related (Masur et al.1989).

This consensus is not controversial, having been largely spelt out previously (Anderson et al. 1990, Fahey et al.1990, Bird 1992), and reflects the conservatism and caution of the profession, and the practicalities and costs of testing.

However, newer concepts in our understanding of immune activation and the subsets of $\mathrm{T}$ helper cells and their cytokine profiles should prompt us to look for new and better indicators of progression. Candidate indicators include numbers of memory and naive lymphocytes using the CD45 isoforms CD45RO (memory) and CD45RA (naive), particularly in paediatric practice, and the indirect evidence of $\mathrm{T}$ helper subsets and their activation from levels of cytokines e.g. IFN $\gamma$, IL2,TNF for $\mathrm{T}_{\mathrm{H}} 1$; IL4, IL6, IL10 for $\mathrm{T}_{\mathrm{H}} 2$ (Clerici \& Shearer 1993, Bentwich et al. 1995) or of transcription factors which regulate $\mathrm{T}$ lymphocyte activation such as NF-KB or NFAT1 (Crabtree 1989, Serfling et al.1989).

All of these assays are currently rather elaborate to perform, involving manipulation and cell culture of high risk cell samples. The technology required for meaningful assays may become simpler if stable products (soluble receptors or other surface antigens) found in serum of patients become measurable, or if quantitation of specific messenger RNA for these products in cell samples became possible at realistic expense. The history of immunological research has often been marked by serendipity - 'making discoveries, by accident or sagacity, of things they were not in quest of' the technologies to investigate AIDS have seemed to develop by chance in parallel with the epidemic. The further translation of basic techniques into practical monitoring technology should be awaited with optimism.

\section{REFERENCES}

Anderson RE, Lang W, Shiboski S, Royce R, Jewell N, Winkelstein W Jr 1990. Use of beta 2microglobulin level and CD4 lymphocyte count to predict development of acquired immunodeficiency syndrome in persons with human immunodeficiency virus infection. Arch Int Med 150: 73-77.

Bentwich Z, Kalinkovich A, Weisman Z 1995. Immune activation is a dominant factor in the pathogenesis of African AIDS. Immunol Today 16: 187-191.

Bird AG 1992.Clinical and immunological assessment of HIV infection. J Clin Pathol 45: 850-854.

Bland JM, Altman DG 1986. Statistical methods for assessing agreements between measurements. Biochemica Clinica 11: 399-405.

CDC 1992. Guidelines for the performance of CD4+ Tcell determinations in persons with Human Immu- nodeficiency Virus infection. MMWR 41: 1-17.

Clerici M, Shearer GM 1993. A $\mathrm{T}_{\mathrm{H}} 1 \rightarrow \mathrm{T}_{\mathrm{H}} 2$ switch is a critical step in the etiology of HIV infection. Immunol Today 14:107-111.

Clerici M, Stocks NI, Zajac RA, Boswell RN, Lucey DR, Via CS, Shearer GM 1989. Detection of three distinct patterns of $\mathrm{T}$ helper cell dysfunction in asymptomatic human immunodeficiency virus seropositive patients. Independence of CD4+ cell numbers and clinical staging. J Clin Invest 84: 18921899.

Crabtree GR 1989. Contingent genetic regulatory events in T lymphocyte activation. Science 24: 355-361.

Dalgleish AG, Beverley PC, Clapham PR, Crawford DH, Greaves MF, Weiss RA 1984. The CD4 (T4) antigen is an essential component of the receptor for the AIDS retrovirus. Nature 312: 763-767.

Fahey JL, Taylor JM, Detels R, Hofmann B, Melmed R, Nishanian P, Giorgi JV 1990. The prognostic value of cellular and serologic markers in infection with human immunodeficiency virus type 1 . New Engl J Med 322: 166-172.

Francioli P, Clement F, Glauser MP 1984. Beta-2 microglobulin: a sensitive non-specific marker for acquired immune deficiency syndrome. Eur J Clin Microbiol 3: 68-69.

Galai N, Munoz A, Chen K, Carey VJ, Chmiel J, Zhou SY 1993. Tracking of markers and onset of disease among HIV-1 seroconvertors. Stats Med 12: 21332145.

Helbert MR, L'Age-Stehr J, Mitchison NA 1993. Antigen presentation, loss of immunological memory and AIDS. Immunol Today 14: 340-344.

Krohn K, Ranki A, Antonen J, Valle SL, Suni J, Vaheri A, Saxinger C, Gallo RC 1985. Immune functions in homosexual men with antibodies to HTLV-III in Finland. Clin Exp Immunol 60: 17-24.

Masur H, Ognibene FP, Yarchoan R, Shelhamer JH, Baird BF, Travis W, Suffredini AF, Deyton L, Kovacs JA, Falloon J, et al. 1989. CD4 counts as predictors of opportunistic pneumonias in human immunodeficiency virus (HIV) infection. Ann Intern Med 111: 223-231.

Owainati AA, Pereira RS, Chippendale K, Newman W 1990. Study of techniques for lymphocyte subset quantitation. Department of Health Medical Devices Directorate MDD/90/63.

Pereira RS, Platts-Mills TAE 1982. Lymphocyte subsets in hypogammaglobulinaemia. Clin Haematol 11: 589-605.

Robinson G, Morgan L, Evans M, McDermott S, Pereira S, Wansbrough-Jones M, Griffin GE 1992. Effect of type of haematology analyser on CD4 count. Lancet 340: 485 .

Serfling E, Barthelmas R, Pfeuffer I, Schenk B, Zarius S, Swoboda R, Mercurio F, Karin M 1989. Ubiquitous and lymphocyte-specific factors are involved in the induction of the mouse interleukin 2 gene in T lymphocytes. EMBO J 8: 465-473.

Zolla-Pazner S, William D, El-Sadr W, Marmor M, Stahl R 1984. Quantitation of beta 2-microglobulin and other immune characteristics in a prospective study of men at risk for acquired immune deficiency syndrome. JAMA 251: 2951-2955. 